\title{
ANÁLISE SENSORIAL E ELABORAÇÃO DE BISCOITO AMANTEIGADO ADICIONADO DE FARINHA DE MARACUJÁ (Passiflora edulis)
}

\author{
F. K. T. de BARROS ${ }^{1}$, M. M. de A. SOUSA ${ }^{1}$, S. E. B. dos SANTOS ${ }^{1}$, M. do C. P. RODRIGUES ${ }^{1}$ \\ ${ }^{1}$ Universidade Federal do Ceará, Departamento de Engenharia de Alimentos \\ E-mail para contato: fernandaktbarros@hotmail.com
}

\begin{abstract}
RESUMO - O maracujá gera muitos resíduos, podendo estes serem inseridos na alimentação humana. Este estudo teve como objetivo verificar a aceitação da inserção da farinha da casca de maracujá em biscoitos do tipo amanteigados. Fez-se o uso da adição dessa farinha em três níveis 10\%, 20\% e 30\%. Consultou-se 42 provadores não treinados, utilizando-se testes sensoriais afetivos (Escala Hedônica e Ordenaçãopreferência) e teste de Intenção de compra. Os resultados dos testes afetivos mostraram alta porcentagem de aceitação dos 3 biscoitos, excetuando o biscoito adicionado $10 \%$ de farinha de maracujá no atributo crocância. Os biscoitos adicionados com 20\% e 30\% de farinha de maracujá possuíram também uma alta porcentagem na Intenção de compra. Concluímos que os biscoitos foram aceitos, que não houve diferença significativa com $5 \%$ de significância e que os biscoitos adicionados $20 \%$ e $30 \%$ de farinha de maracujá foram aprovados na Intenção de compra.
\end{abstract}

\section{INTRODUÇÃO}

O biscoito é o produto obtido pela mistura, amassamento e cozimento conveniente de massa preparada com farinhas e outras substâncias alimentícias. A história do biscoito vem desde o tempo dos homens das cavernas. Nessa época, quando o homem já comia alguns grãos, triturando-os com os dentes, teve a ideia de moê-los com pedra. Depois passou a misturar com água e secá-los ao fogo.

Com a crescente expansão da indústria alimentícia também há o aumento crescente da produção de resíduos e com isso preocupações com os possíveis destinos desse resíduo. A destinação imprópria para os resíduos de certas frutas, como por exemplo o maracujá, cultivado em larga escala em quase todo o Brasil, a quantidade de resíduos (cascas mais sementes) produzidos por toneladas de suco processado é bastante expressivo e portanto é muito importante que um número cada vez maior de soluções para o aproveitamento dos mesmos seja possível incentivandose o desenvolvimento de pesquisas.

Os resíduos provenientes da indústria de alimentos envolvem quantidades apreciáveis de cascas, caroços e outros. Esses materiais servem como fonte de proteínas, enzimas e óleos essenciais, passíveis de recuperação (Coelho et al., 2001). Podendo ser observado que esse resíduo apresenta bons valores nutricionais, contribuindo para uma alimentação balanceada.

O maracujá amarelo (Passiflora edulis flavicarpa Degener), também conhecido como “maracujá azedo", é originário do Brasil (Andersen e Andersen, 1989). Os frutos maiores apresentaram menor porcentagem de casca (média de 53\% da massa total do fruto) que os frutos 
menores, esses com média de 67\% de casca (Coelho et al., 2011). Visto que mais da metade do fruto é casca e que a forma para a obtenção da farinha é fácil, justifica o manejo desse resíduo.

O trabalho de Venturini (2010) mostrou que a polpa do maracujá contém vitaminas do tipo A e $\mathrm{C}$, sais minerais e fibras, no entanto, a sua casca apresenta propriedades funcionais. A casca do maracujá, em especial a parte branca, é bastante rica em vitamina B3, ferro, cálcio e fósforo. Com isso já se pode ver os benefícios que a casca do maracujá pode trazer ao ser humano, uma vez que o ferro previne anemia, o cálcio fortalece os ossos, o fósforo é importante na formação celular (Córdova et al., 2005). Quanto à composição de fibras, a casca do maracujá constitui produto vegetal rico em fibra do tipo solúvel (pectinas e mucilagens), benéfica ao ser humano. Ao contrário da fibra insolúvel (contida no farelo dos cereais) que pode interferir na absorção do ferro, a fibra solúvel pode auxiliar na prevenção de doenças (Rocco, 1993; Bina, 2004). A pectina, por exemplo, ajuda a diminuir a taxa de glicose e colesterol no sangue.

A farinha de maracujá se mostra como ingrediente funcional passível de substituir a farinha de trigo na composição original dos biscoitos amanteigados, tendo como objetivo enriquecer esse produto tanto quanto na quantidade de vitaminas, quanto na quantidade de fibras.

A pesquisa tem como objetivo a elaboração e verificação por métodos sensoriais de uma massa a base de farinha de trigo adicionada em três percentuais distintos (10\%; 20\%; 30\%) de farinha de maracujá. Foram utilizados os testes Ordenação-Preferência e Escala Hedônica, com a finalidade de analisar a preferência dos consumidores e a aceitação, respectivamente. Além disso, analisou-se a atitude de compra, caso o produto estivesse disponível no mercado.

\section{MATERIAIS E MÉTODOS}

Foram feitas três massas de biscoito diferindo apenas na quantidade de farinha de maracujá. Seguindo as especificações abaixo:

Massa com 10\% de adição de farinha de maracujá: 160g de açúcar, 432g de farinha de trigo, $400 \mathrm{~g}$ de margarina, $48 \mathrm{~g}$ de farinha da casca de maracujá, 4 colheres de café de essência de baunilha (5ml), misturou-se os ingredientes em um recipiente plástico com auxílio das mãos. Em seguida foi feito o formato do biscoito levemente esférico com média de 4 centímetros de diâmetro e levado ao forno a $200^{\circ} \mathrm{C}$ por 25 minutos.

Massa com 20\% de adição de farinha de maracujá: 160g de açúcar, 384g de farinha de trigo, 400 g de margarina, 96g de farinha da casca de maracujá, 4 colheres de café de essência de baunilha (5ml), misturou-se os ingredientes em um recipiente plástico com auxílio das mãos. Em seguida foi feito o formato do biscoito levemente esférico com média de 4 centímetros de diâmetro e levado ao forno a $200^{\circ} \mathrm{C}$ por 25 minutos.

Massa com 30\% de adição de farinha de maracujá: 160g de açúcar, 336g de farinha de trigo, $400 \mathrm{~g}$ de margarina, $144 \mathrm{~g}$ de farinha da casca de maracujá, 4 colheres de café de essência de baunilha (5ml), misturou-se os ingredientes em um recipiente plástico com auxílio das mãos. Em seguida foi feito o formato do biscoito levemente esférico com média de 4 centímetros de diâmetro e levado ao forno a $200^{\circ} \mathrm{C}$ por 25 minutos. 
A análise sensorial foi realizada no Laboratório de Análise Sensorial do Departamento de Tecnologia de Alimentos (DETAL) da Universidade Federal do Ceará (UFC).

Para a realização da análise, as amostras foram divididas em porções para que pudessem ser servidas aos provadores, seguindo tamanhos aproximados para as três amostras. As amostras foram servidas aos provadores de forma monádica para a realização do teste Escala hedônica e logo após servidas juntas, para a realização dos outros testes (Ordenação preferência e Atitude de compra). Foram aplicados um teste de aceitação com uma escala estruturada de nove pontos (Escala Hedônica) e o teste de Ordenação-Preferência, com 42 provadores não treinados.

\section{RESULTADOS E DISCUSSÃO}

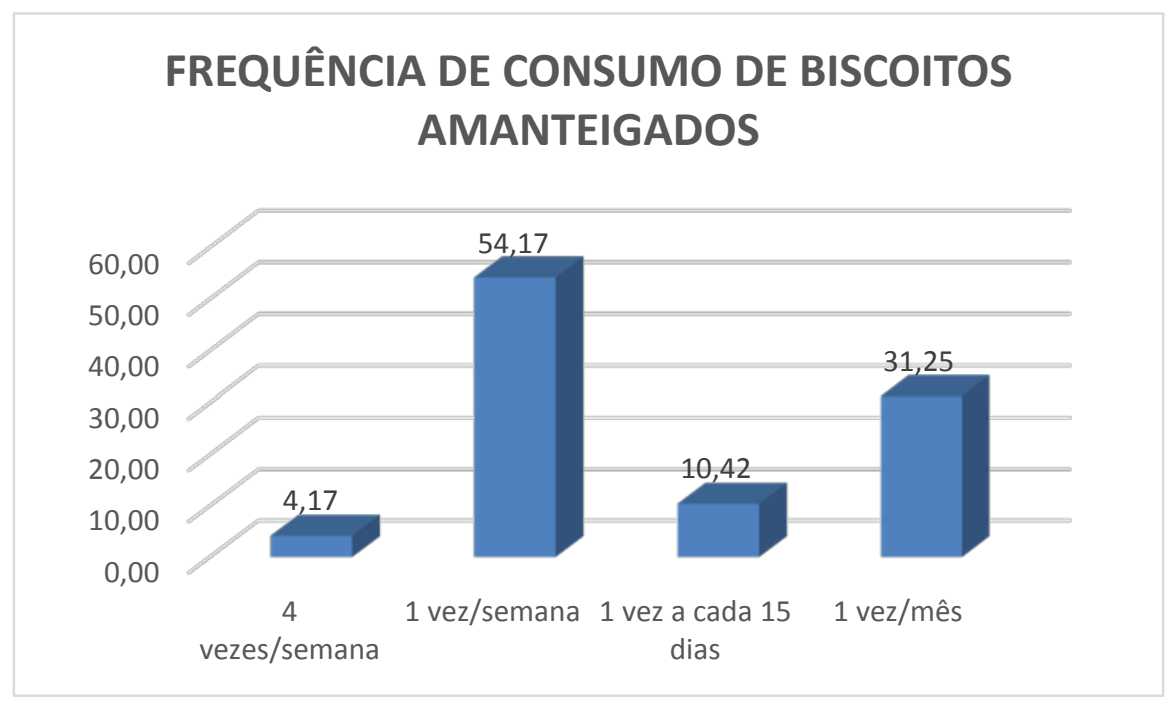

Figura 1 - Histograma de frequência de consumo de biscoitos amanteigados.

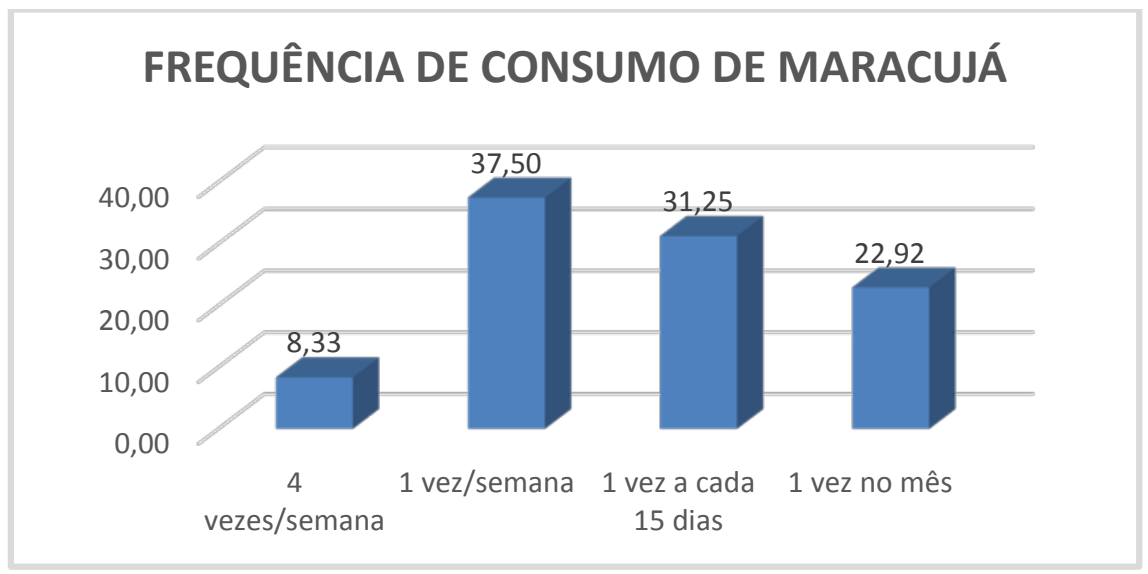

Figura 2 - Histograma de frequência do consumo de maracujá. 


\section{INTENSIDADE DE GOSTO POR BISCOITOS} AMANTEIGADOS

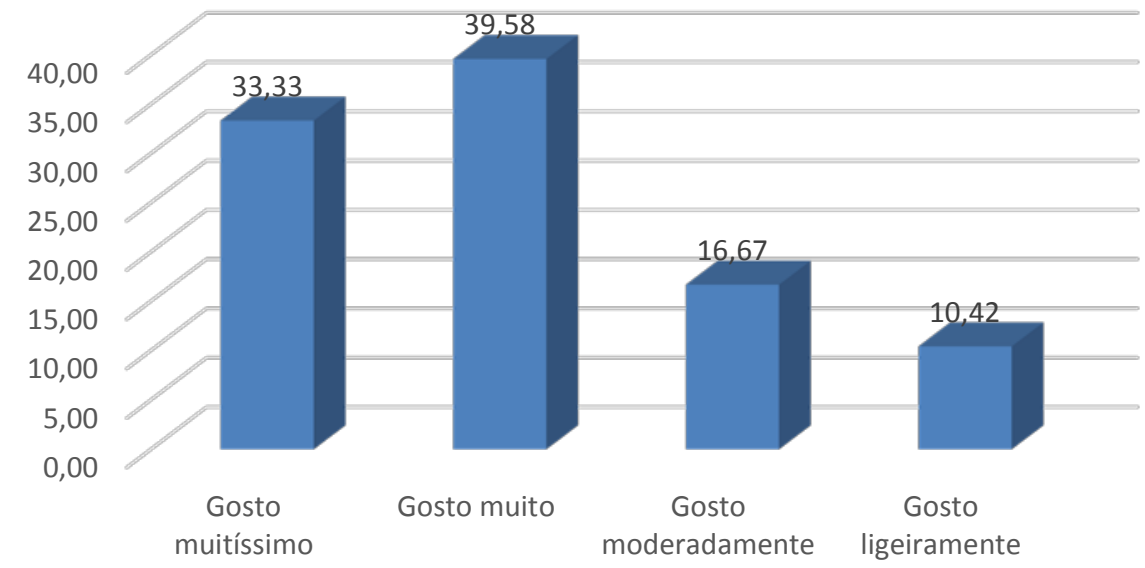

Figura 3 - Histograma de frequência da intensidade de gosto por biscoitos amanteigados.

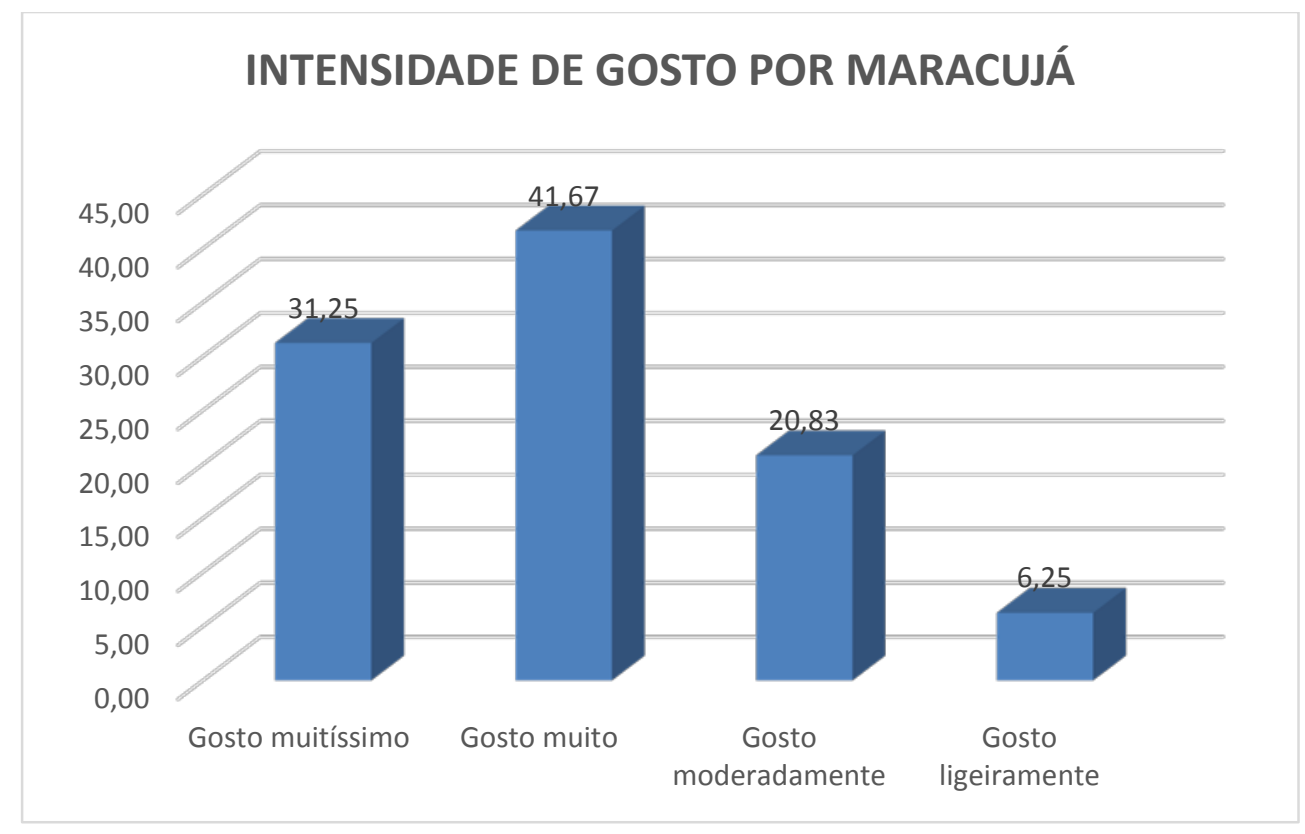

Figura 4 - Histograma de frequência da intensidade de gosto por maracujá.

Conforme as Figuras 1 e 2 referente ao consumo de biscoitos e de maracujá, respectivamente, ambos possuem uma porcentagem alta na frequência de consumo. As Figuras 3 e 4 referentes a intensidade de gosto por biscoitos amanteigados e por maracujá, respectivamente, também foi observado que os provadores gostam desses alimentos, apresentando uma frequência considerada alta $(<70 \%)$. Isso mostra que os provadores são realmente consumidores desses produtos, tornando as respostas dos testes mais verídicas. 


\subsection{Escala Hedônica}

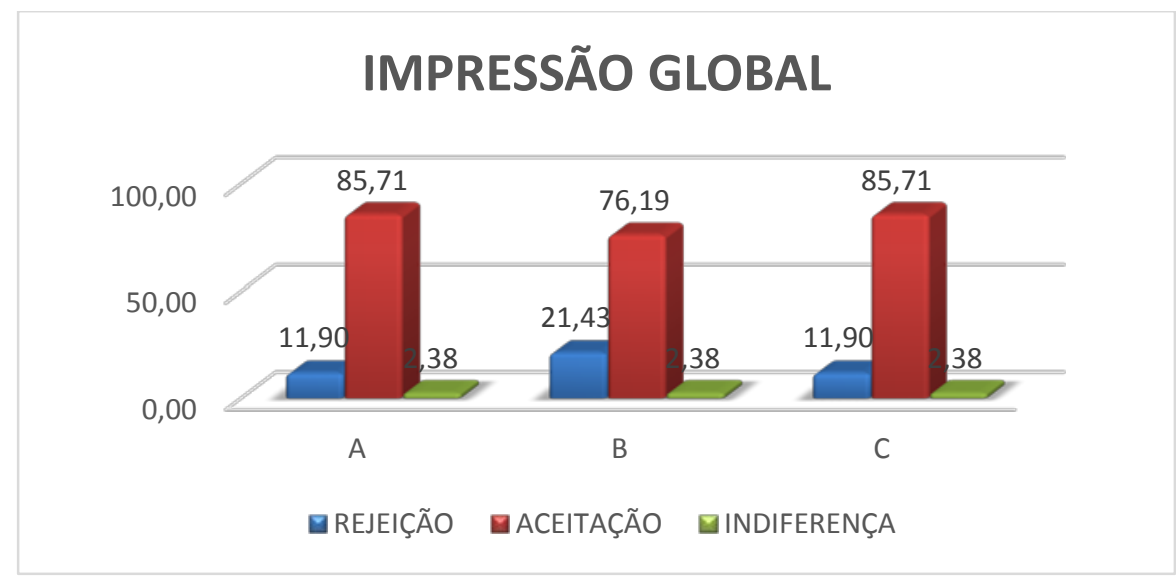

Figura 5 - Histograma de frequência para impressão global.

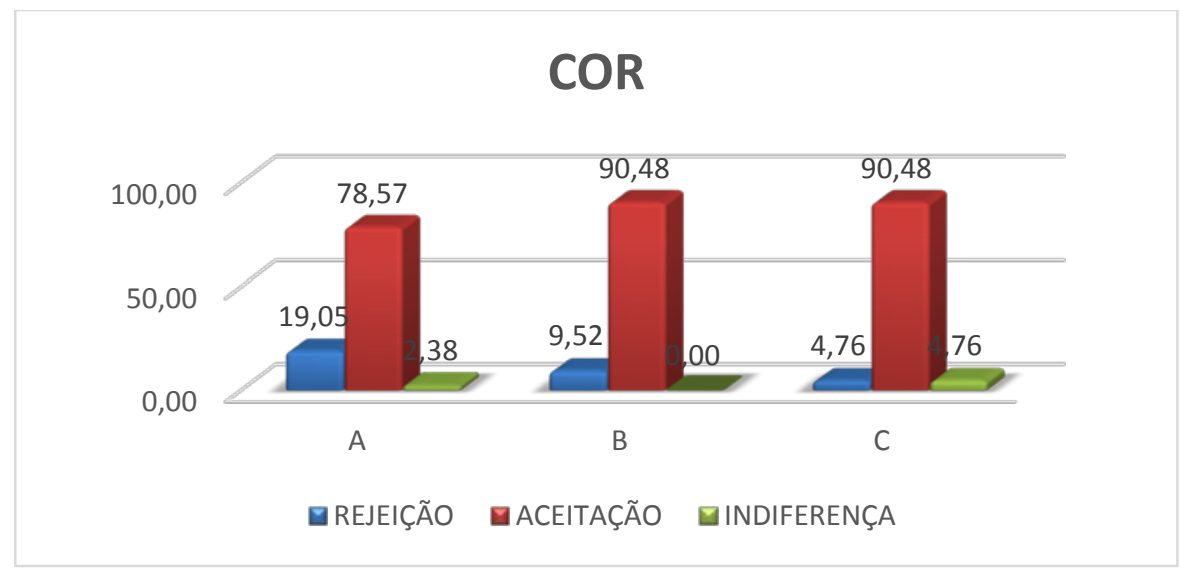

Figura 6 - Histograma de frequência para cor.

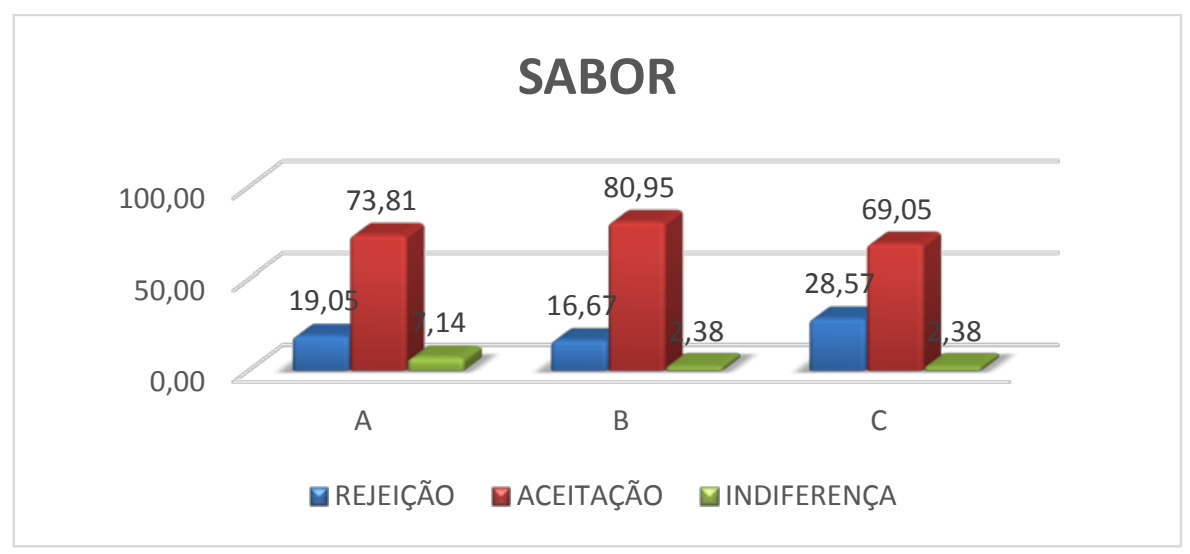

Figura 7 - Histograma de frequência para sabor. 


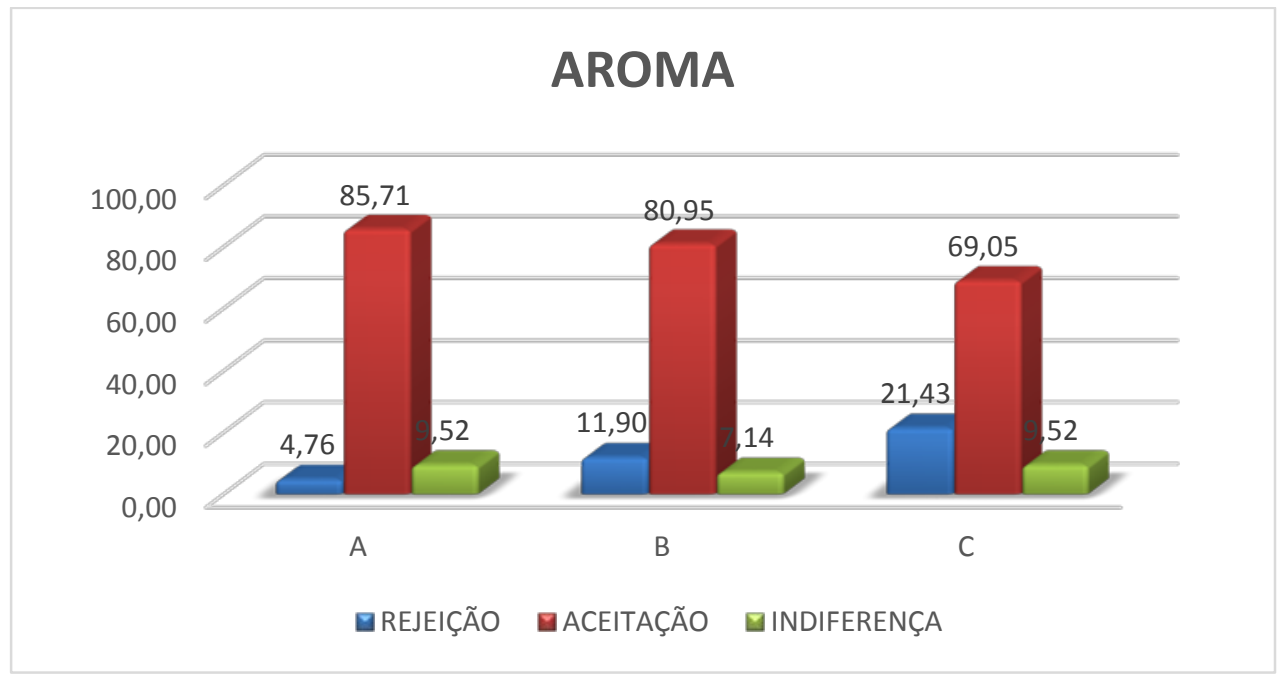

Figura 8 - Histograma de frequência para aroma.

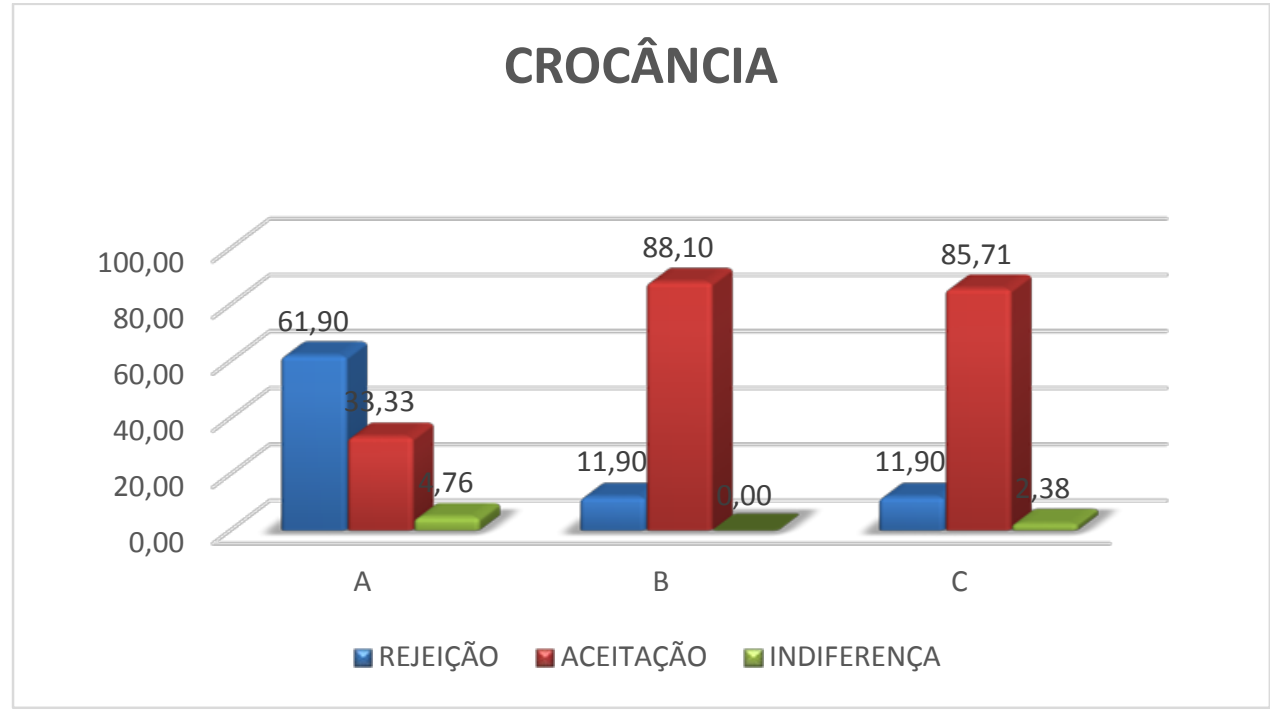

Figura 9 - Histograma de frequência para crocância.

De acordo com as Figuras 5 e 6 para os aspectos Impressão global e Cor, respectivamente, todas as amostras obtiveram índices superiores a 70\% na faixa de aceitação. Nas Figuras 7 e 8, que correspondem respectivamente as amostras de sabor e aroma, a amostra C foi a única a obter índices inferiores a 70\% na zona de aceitação. Como mostra a Figura 9, em Crocância a amostra A obteve índice inferior a $70 \%$ na zona de aceitação. Isto pode ser explicado, na ficha do teste sensorial solicitou-se aos provadores que colocassem pontos positivos e negativos para as amostras. Os mais frequentes estão listados abaixo:

Pontos negativos: Amostra A: não crocante, mole; Amostra B: sabor residual amargo e de queimado, textura dura; Amostra C: sabor residual amargo e de queimado. 


\subsection{Ordenação-preferência}

No teste ordenação preferência realizado com 42 provadores obteve-se as diferenças:

Tabela 01 - Diferença entre as amostras

\begin{tabular}{|l|r|}
\hline$A-B=$ & 16 \\
\hline$A-C=$ & 5 \\
\hline$B-C=$ & 10 \\
\hline
\end{tabular}

A diferença critica segundo a Tabela 1 de Macfarlane e Newel é de 22. Ou seja as amostras não diferem com $5 \%$ de significância. O que significa que as amostras foram igualmente preferidas pelos provadores.

\subsection{Intenção de Compra}

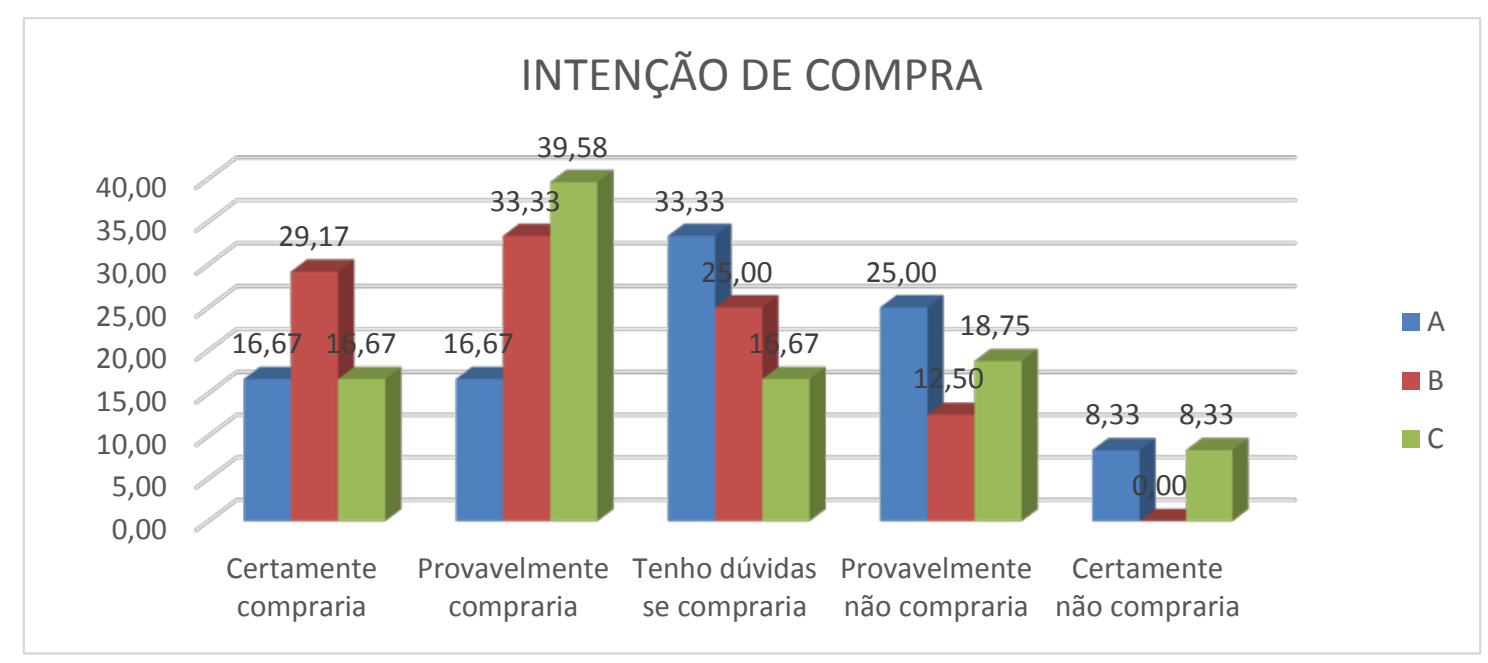

Figura 10 - Histograma de frequência da intenção de compra para as três amostras.

As análise das figuras apresentadas resultou no Histograma de frequência da intenção de compra para as três amostras, conforme mostra a Figura 10, onde a amostra A possui aproximadamente $32 \%$ na faixa considerada positiva do gráfico (“Certamente compraria” e "Provavelmente compraria”). A amostra B possui aproximadamente $60 \%$ e a amostra C possui 54\%. Apenas as amostras B e C possuíram uma frequência acima de $50 \%$, mostrando que provavelmente essas seriam bem aceitas caso fossem comercializadas. A amostra A, por sua vez, possui uma frequência abaixo de 50\%. No atributo crocância do teste Escala hedônica, a amostra A apresenta uma porcentagem baixa, podendo ser um dos motivos que provavelmente essa amostra tenha recebido um valor baixo na intenção de compra, pois esse atributo é crucial na qualidade e na escolha de um biscoito. 


\section{REFERÊNCIAS}

ANDERSEN, O.; ANDERSEN, V.U. As frutas silvestres brasileiras. 3.ed. São Paulo: Globo, 1989. 203 p.

BINA, M. Dados nutricionais do maracujá. Disponível em: <www.saudelar.com>. Acesso em 25 de novembro 2013.

COELHO, M. A. Z.; LEITE, S. G. F.; ROSA, M. DE F. Aproveitamento de resíduos agroindustriais: produção de enzimas a partir da casca de coco verde. Boletim CEPPA. v.19, n.01, p.33-42, jan/jun, 2001.

COELHO, A. A.; CENCI, S. A.; RESENDE, E. D. Rendimento em suco e resíduos do maracujá em função do tamanho dos frutos em diferentes pontos de colheita para o armazenamento. Revista Brasileira de Produtos Agroindustriais, Campina Grande, v.13, n.1, p.55-63, 2011.

CÓRDOVA,K. R. V.; GAMA,T. M. M. T B.; WINTER,C. M. G.; KASKANTZIS NETO,G.; FREITAS, R. J. S. de. Características físico-químicas da casca do maracujá amarelo (Passiflora edulis Flavicarpa Degener) obtido por secagem. B.CEPPA, Curitiba, v. 23, n.2, pág.220-230.2005.

ROCCO, C.S. Determinação de fibra alimentar total por método gravimétrico não-enzimático. Curitiba, 1993, 102 p. Dissertação (Mestrado), Departamento de Engenharia Química, Setor de Tecnologia, Universidade Federal do Paraná.

VENTURINI FILHO, W. G. Bebidas não alcoólicas: Ciência e tecnologia. Editora Blucher. São Paulo. v.2. 2010. 